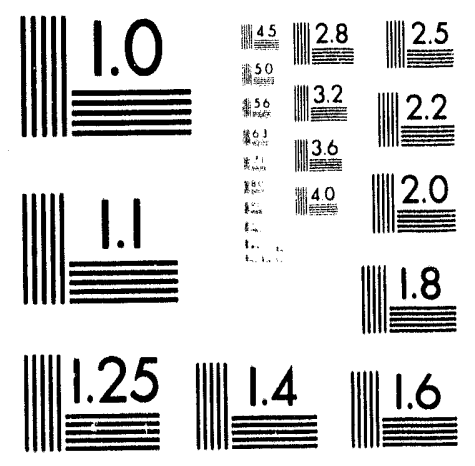



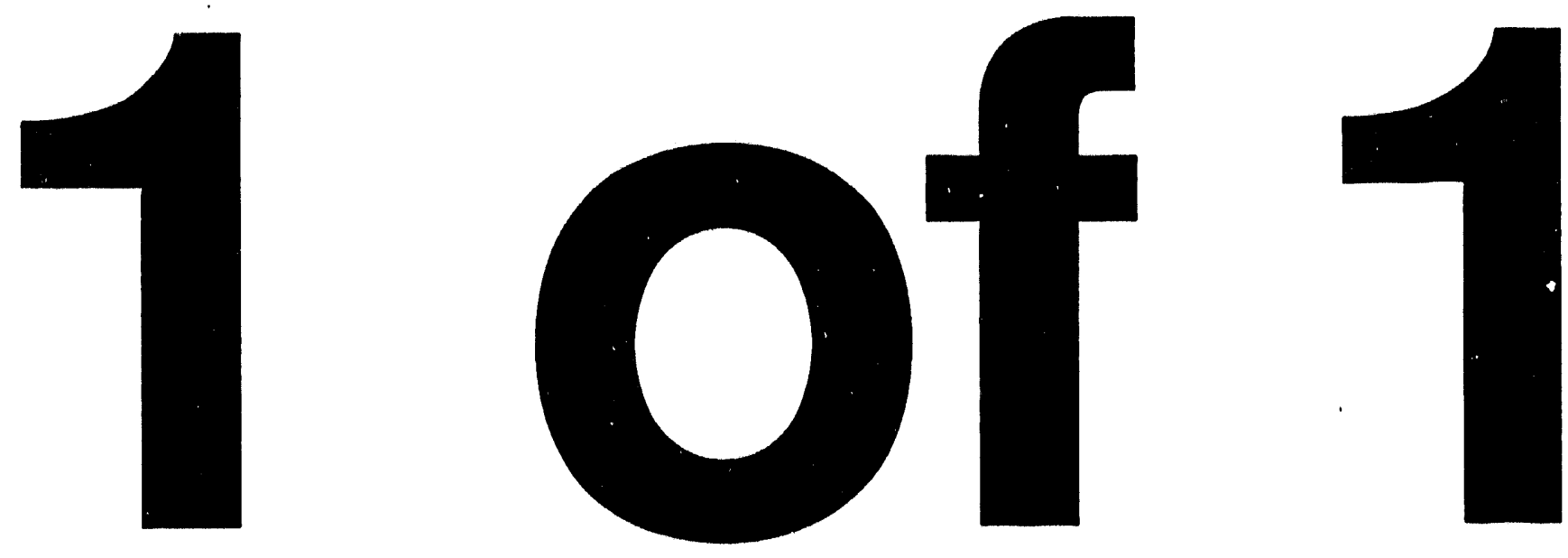
LA-UR -93-3389

TITLE: Design of a 400 MW Power Supply for a $60 \mathrm{~T}$ Pulsed Magnet

AUTHOR(S): J.B. Schillig, H.J.Boenj.g, J.D. Rogers and J.R. Sims

SUBMITTED TO: Thirteenth International Conference on Magnet Technology

\section{DISCLAIMER}

This report was prepared as an account of work sponsored by an agency of the United States Government. Neither the United States Government nor any agency thereof, not any of their employees, makes any warranty, express or implied, or assumes any legal liability or responsibility for the accuracy, completeness, or usefulness of any information, apparatus, product, or process disclosed, or represents that its use would not infringe privately owned rights. Reference herein to any specific commercial product, process, or service by trade name, trademark, manufacturer, or otherwise does not necessarily constitute or imply its endorsement, recommendation, or favoring by the United States Government or any agency thereof. The views and opinions of authors expressed herein do not necessarily state or reflect those of the United States Government or any agency thereof.

$\triangle E / V E O$

OCT 071993

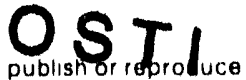

By acceptance of this article. the publisher recognizes that the US Government retainis a nonexclusive. royally-fiee license to publishor reproluce the published form of this contribution. of to allow others to do so. for US Gavernment purposes

The $I$ os Alamos National Laboratory requests that the publisher identily this article as work pertormed under the auspices of the $U S$ Department of Energy
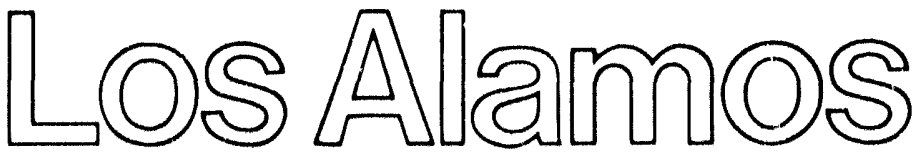

Los Alamos National Laboratory Los Alamos,New Mexico.87545 


\title{
Design of a 400 MW Power Supply for a 60 T Pulsed Magnet
}

\author{
J. B. Schillig, H. J. Boenig, J. D. Rogers and J. R. Sims \\ National High Magnetic Field Laboratory at Los Alamos National Laboratory \\ Los Alamos, New Mexico 87545
}

\begin{abstract}
The National High Magnetic Fleld Laboratory at Los Alamos designs a magnet that produces magnetic fields of up to $60 \mathrm{~T}$ for as long as $100 \mathrm{~ms}$. The power and energy to operate the magnet Is provided by a $1430 \mathrm{MVA}, 24 \mathrm{kV}$ energy storage generator. Three modular design power supplles convert the ac-power produced by the generator into controlled dc-power needed by the three coll groups of the eight coll magnet. The modules are rated at $4 \mathrm{kV}$ no-load voltage and $20 \mathrm{kA}$ full-load current for up to 2 seconds once every hour, each Including a 12 . pulse, line-commutated rectifler designed to operate In the $66 \mathrm{~Hz}$ to $42 \mathrm{~Hz}$ pulse operation range of the generator. A short description of the overall $60 \mathrm{~T} / 100 \mathrm{~ms}$ magnet system is given, followed by a detalled description of the power converter system design.
\end{abstract}

\section{INTRODUCTION}

The National High Magnetic Field Laboratory at Los Alamos designs and builds a $60 \mathrm{~T} / 100 \mathrm{~ms}$ long-pulse magnet system. The system consists of the following major subsystems:

- $60 \mathrm{~T} / 100 \mathrm{~ms}$ magnet

- power converters

- power source.

The $60 \mathrm{~T} / 100 \mathrm{~ms}$ magnet requires about $260 \mathrm{MW}$ of peak dc-power during a "design-pulse." At $60 \mathrm{~T}$ about $90 \mathrm{MJ}$ are stored in the magnetic field of the magnet. During a "designpulse," that lasts about 2 seconds, the coils dissipate approximately $75 \mathrm{MJ}$.

These power and energy requirements, combined with the load pattern, are beyond the capabilities of most utility systems. An intermediate, high-power and high-energy storage system has to be used as a buffer.

The 1430 MVA generator facility, which Los Alamos National Laboratory commissioned in the fall of 1990, is an ideal power and energy source for this type of load [1]. In its present configuration the generator facility can deliver up to about $780 \mathrm{MJ}$ to an experiment at a pcak power of up to about 1000 MVA.

The power converter system consists of thyristor based power supplies used to convert the ac-power available at the generator terminals into variable voltage de-power needed to operate the magnet. The power supplies allow the magnet currents to be controlled to provide a variety of pulse shapes. They also allow to extract the energy stored in the magnetic field within a very short time span, be it for operation or safcty reasons.

Manuscript received September 20, 1993. This work was supported by National High Magnetic Field Laboratory and National Science Foundation, cooperative agreement No. DMR-9016241.

\section{A. The $60 \mathrm{~T} / 100 \mathrm{~ms}$ Magnet}

The $60 \mathrm{~T} / 100 \mathrm{~ms}$ magnet consists of eight coaxially nested coils and is designed to produce $60 \mathrm{~T}$ for $100 \mathrm{~ms}$. The coils are made of aluminum oxide dispersion strengthened copper. Coil 8, the outermost coil, is self-supporting. Coils 7 through 1 , with coil 1 being the innermost coil, each have a high strength, nitrogen-alloyed stainless steel support shell. The coils are assembled within a support structure and the whole assembly is installed inside a stainless steel dewar. The magnet is operated at $77 \mathrm{~K}$. Sce [2] for more details.

Electrically, the magnet is divided into three coil groups. Group 3 (coil 8), group 2 (coils 6 and 7) and group 1 (coils 5 through 1) are each powered by separate power supplies, as shown in Fig. 1.

\section{B. The Power Source}

The power source consists of a synchronous generator with a nominal power output of $1430 \mathrm{MVA}$ at $24 \mathrm{kV}$ terminal voltage. The $230 \mathrm{t}$ shaft train of the machine set is used as inertial energy storage. The energy is stored as kinctic energy in the rotating masses of the shaft train. At $1800 \mathrm{rpm}(60 \mathrm{~Hz})$, the nominal speed of the generator, about $1270 \mathrm{MJ}$ are stored in the shaft train. The upper speed limit for pulse operation is $1980 \mathrm{rpm}(66 \mathrm{~Hz})$ and the lower limit is $1260 \mathrm{rpm}(42 \mathrm{~Hz})$, allowing up to about $915 \mathrm{MJ}$ to be extracted during a pulse.

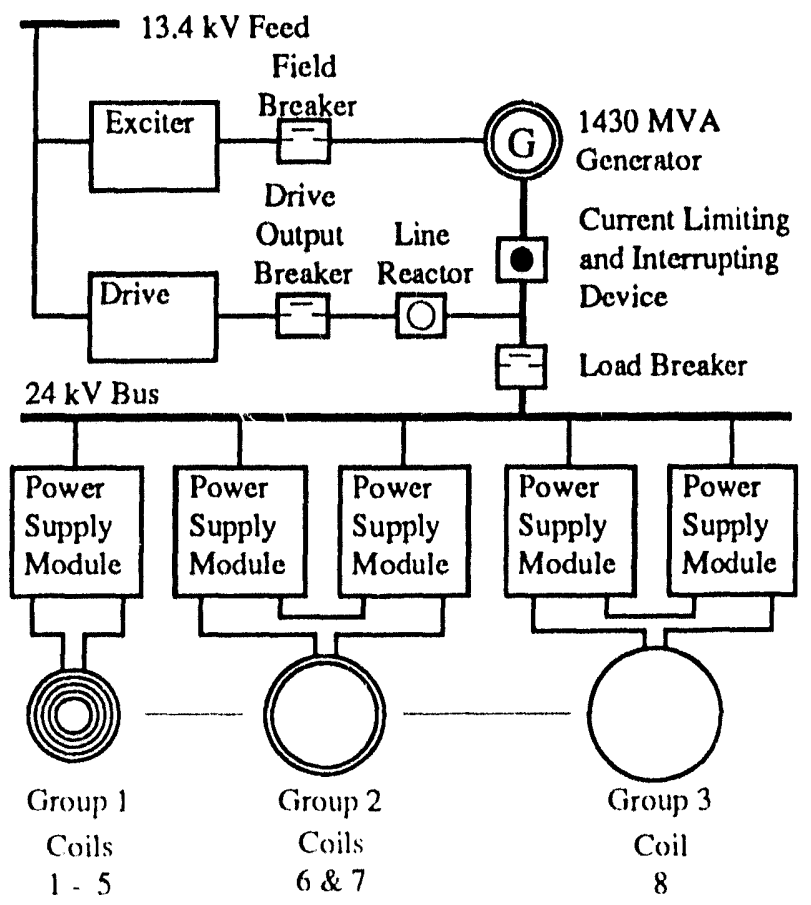

Fig. 1. Overall $60 \mathrm{~T} / 100 \mathrm{~ms}$ magnet sytem layout 
However, pulses are usually started at or below $1800 \mathrm{rpm}$ to limit fatigue of the rotor materials, leaving about $650 \mathrm{MJ}$ of extractable energy. In the present configuration of the generator facility, the drive system, the current limiting and interrupting device, the load breaker and the excitation transformer limit the energy available to about $780 \mathrm{MJ}$ and the power output of the generator to about 1000 MVA.

By adding a $200 \mathrm{t}$ flywheel and upgrading or modifying the limiting elements mentioned above, a peak power output of up to 2000 MVA and up to $2000 \mathrm{MJ}$ of extractable energy can be made available.

A $6 \mathrm{MW} / 4 \mathrm{kV}$ load-commutated inverter drive system, directly connected to the stator of the generator, is used to accelerate or decelerate the shaft train, or to maintain a certain shaft speed. Before each pulse the generator is disconnected from the drive and connected to the load. The generator terminal voltage is then raised to $\leq 24 \mathrm{kV}$. During a pulse the shaft speed drops or increases in proportion to the amount of energy extracted or regenerated by the experiment and the amount dissipated by machine losses. After a pulse the generator is reconnected to the drive.

\section{THE POWER CONVERTERS}

\section{A. Basic Requirements}

- The power converter system has to be designed to meet the voltage, current and power demands of the $60 \mathrm{~T} / 100 \mathrm{~ms}$ magnet.

- The power converter system, together with the magnel, has to provide a $60 \mathrm{~T}$ field for $100 \mathrm{~ms}$ with a ripple of less than $0.1 \%$.

- During the $100 \mathrm{~ms}$ flat-top time the field $(60 \mathrm{~T})$ shall remain within a $0.2 \%$ wide band.

- It shall be possible to perform one pulse every hour.

\section{B. General Design Aspects}

The design of the converter system for the $60 \mathrm{~T} / 100 \mathrm{~ms}$ magnet is mainly driven by the constraints governing the magnet design and only to a lesser degree by limitations of power supply components and schemes, and limitations given by the power source.

A modular design of the power supplies is preferred. This allows needs of various magnet configurations to be satisficd by simply rearranging modules and to meet the necds of future, higher field magnets by adding new identical modules. A modular design also minimizes the spare-part inventory and lowers the operation and maintenance cost.

However, to minimize the complexity of the power supplies, the control and protection systems, as well as the power wiring, the number of modules has to be kept to a minimum.

\section{Basic Power Supply Layout}

I) Layout procedure: Optimizing the stress levels across the whole magnet and minimizing the volume of the magnet required the current densities in the inner coils to be chosen considerably higher than in the outer coils. This implies, given certain temperature or temperature rise limits, that the pulse duration for the inner coils be shorter than for the outer coils. A magnet design with multiple coils is the consequence. Yet another consequence is that multiple independent power supplies are needed.

The basic magnetic and mechanical design of each magnet version was done using a closed-form analytical model. A circuit analysis program was then used to model the electrical and thermal behavior of the design. This model also allowed the simulation of the approximate behavior of the various power supply versions and that of the generator. The simulation results were then used to evaluate and modify the magnet designs and the power supply configurations.

With these tools the configuration shown in Fig. 1, with three power supplies and five power supply modules, was developed.

The basic layout of a power supply module is shown in Fig. 2. Each power supply module is rated at $80 \mathrm{MW}$ with $4 \mathrm{kV}$ no-load voltage and $20 \mathrm{kA}$ full-load current, adding up to a total nominal de-power of $400 \mathrm{MW}$ for the overall converter system.

2) Circuit analysis: The circuit model used to analyze the overall magnet system includes the following main features:

- A model of the magnet including all the self and mutual inductances and all resistances of the coils, including the temperature and ficld dependence of the coil materials conductivity. It also takes into account the enthalpy of the conductor materials. The support shells were not included in the model. Hand calculations show that, for the rise times involved, their influence is minimal.

- An empirical model for each power supply, consisting of a controlled dc-voltage source. It takes into account the voltage drop due to commutation and to reduced generator output voltage. It also includes a model of the time delays associated with the thyristor firing. This feature was not used for the basic magnet and power supply layout.

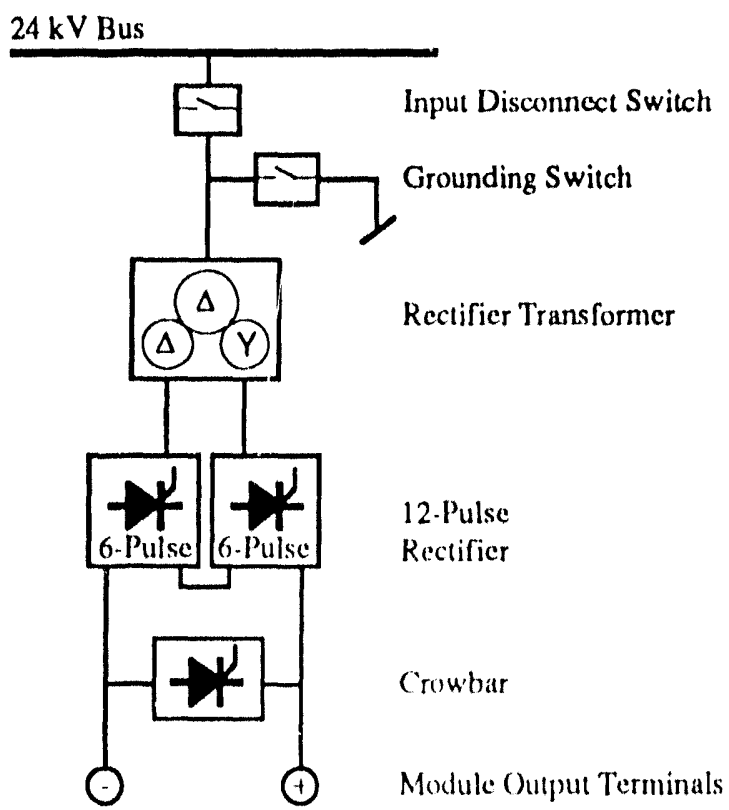

Fig. 2. Power supply module layout 
- An empirical model of the generator that takes into account the changes of the shaft speed due to machine and power supply losses and changes due to extracted or regenerated energy. The voltage drop at reduced shaft speeds due to the flux limitation of the generator and the drop due to the power supply commutation are modeled. The generators voltage-control response was not included.

- A current control feedback loop with a feedback filter and a PID-controller for each power supply. For the magnet and power supply layout only the proportional feedback was used. The feedback filter was not used.

Figures 3 through 7 show the results of a simulation of a "design-pulse" performed with the final magnet and power supply configuration.

Fig. 3 shows a typical plot of the magnetic field versus time. The three charging phases can be easily recognized. Fig. 4 shows the associated coil group currents. Initially group 3 (coil 8 ) is charged to about $17.0 \mathrm{kA}$. At this point the charging of group 2 (coils 7 \& 6) begins with the power supply of group 3 trying to maintain the current. However, the magnetic coupling between group 2 and group 3 is strong enough, that the current in group 3 drops, even though the charging voltage of group 2 is limited to about $72 \%$ and the power supply of group 3 operates at maximum voltage, as shown in Fig. 5. The charging voltage of group 2 is adjusted, such that, when the current of group 2 reaches $18.5 \mathrm{kA}$, the current of group 3 reaches $15.2 \mathrm{kA}$, the value which will be maintained until the end of the $100 \mathrm{~ms}$ flat-top. At this point the charging of group 1 (coils 5 through 1) starts, with groups 2 and 3 trying to maintain their currents. Again, the coupling between group 1 and 2 is strong enough, tha: the charging voltage of group 1 has to be limited to about $76 \%$, to ensure, that when group 1 reaches the flat-top current of $18.5 \mathrm{kA}$, the current of group 2 is back at its flat-top value of $18.5 \mathrm{kA}$. The coupling between group 1 and group 3 is not strong enough to cause the current of group 3 to drop. At this point the flattop starts and the currents of all three groups are maintained constant. The power supply output voltages, however, increase during this phase to compensate for the coil resistance increase due to the ohmic heating, as car be seen in Fig. 5. At the end of the flat-top all three power supplies are

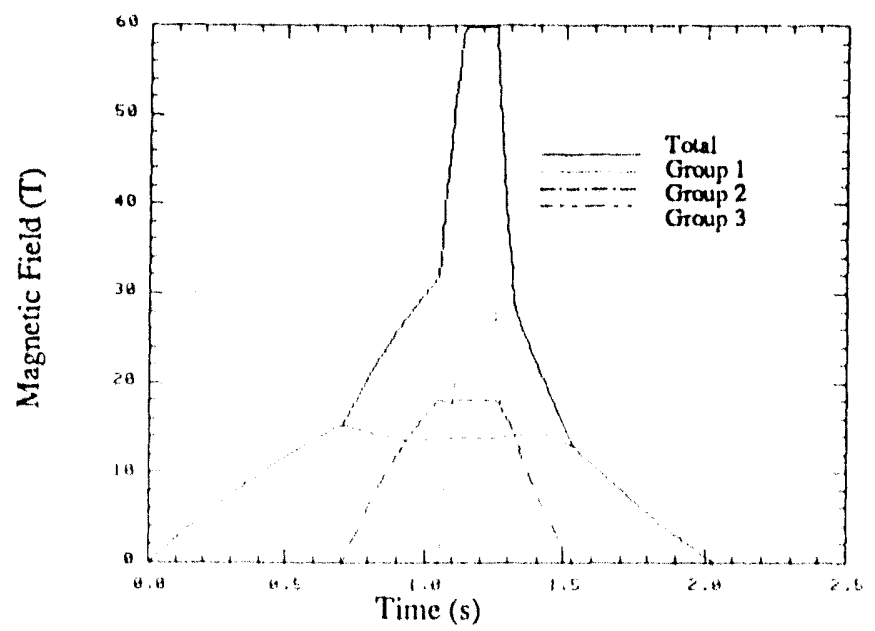

Fig. 3. Magnetic field as a function of time

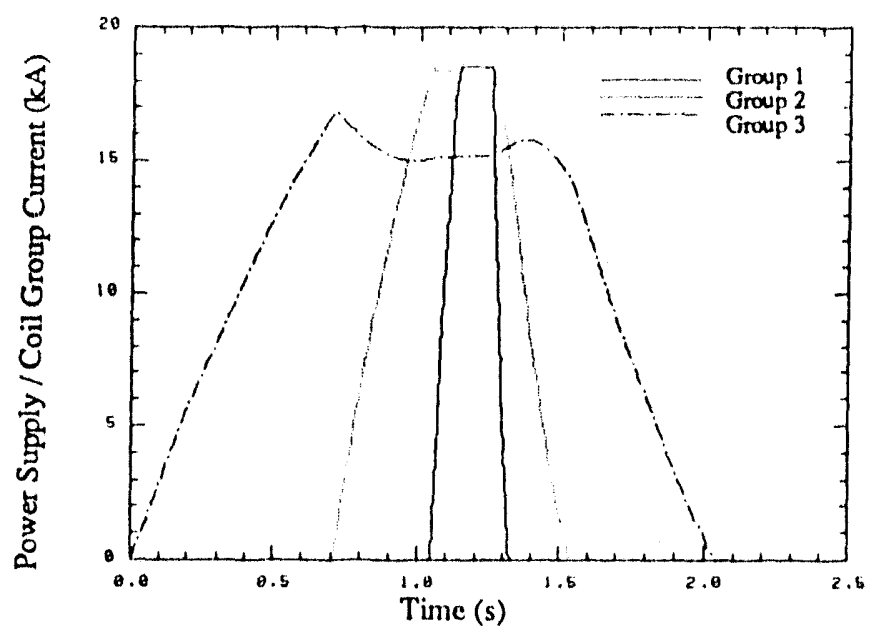

Fig. 4. Coil group / power supply currents as a function of time

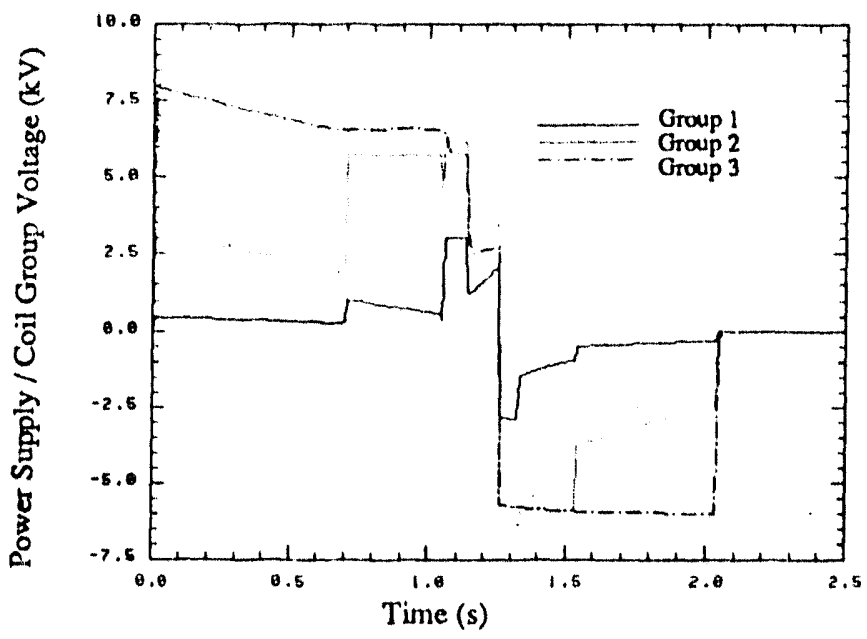

Fig.5. Coil group / power supply voltages as a function of time

switched into the inverter mode to extract as much energy as possible out of the magnet. Fig. 6 shows a typical de-power profile and Fig. 7 shows how the generator shaft speed changes during a pulse.

\section{Power Supply Module Design}

Each power supply module consists of an input disconnect switch combined with a grounding switch, a three-winding rectifier transformer, two series-connected six-pulse thyristor rectifiers, forming a 12-pulse rectifier, and a thyristor crowbar, as shown in Fig. 2.

The rated no-load voltage is $4 \mathrm{kV}$ and the full-load current is $20 \mathrm{kA}$. The full-load voltage of a module has to be at least $3 \mathrm{kV}$ with all five modules operating at full load. In the inverter mode the modules shall provide at least $-2.8 \mathrm{kV}$ over the whole current range.

All components are designed for a 2 second long $20 \mathrm{kA}$ pulse once every hour and can remain energized at $24 \mathrm{kV}$ for 20 s once every hour. In addition, they have to repeatedly 
withstand overvoltages of up to $15 \%$ caused by major load rejections.

To accomodate future designs, up to four modules can be series-connected with the ground connection at the center of the configuration, providing $16 \mathrm{kV}$ across the terminals.

The rectifier transformer has two primary-side taps, one at $24 \mathrm{kV}$ and the other at $21 \mathrm{kV}$, and is designed for up to $20 \%$ overflux capability. This, in conjunction with the $21 \mathrm{kV}$ tap. allows the transformer and thus the power supply module to provide full voltage at generator shaft specds as low as 1500 $\mathrm{rpm}$. The $24 \mathrm{kV}$ tap is used when the full power of the generator is needed to power an experiment.

The core of each power supply module is the 12-pulse rectifier. The 12-pulse configuration is necessary to reduce the ripple of the magnetic field during the flat-top period below the $0.1 \%$ limit and to obtain sufficient control over the coil currents. In addition, individual gate control is required, to obtain the fastest possible rectifier response. The rectificr has to be fully operational across the whole pulse-operation frequency-range of the generator, i.e. $66 \mathrm{~Hz}$ to $42 \mathrm{~Hz}$.

The crowbar is used for protection purposes in case of coil failures, power supply system problems or generator system troubles. The crowbar is sized to handle a $25 \mathrm{kA}$ current decaying with a $3 \mathrm{~s}$ time constant. It can be triggered by the protection system or by the passive overvoltage protection feature of the crowbar control.

\section{E. Control}

Each power supply module has its supervisory control system that monitors the status of all components of the module. The power supply of each coil group has its supervisory control and current control system. The three PID-type current control systems control the coil group currents to follow the predetermined current patterns. These current patterns are the result of computer simulations. These simulations also provide voltage-limit patterns for the individual power supplies. These voltage-limit patterns are needed because of the coupling between the coil groups. They prevent one power supply from driving the others into a situation where they can no longer follow their current patterns. The PID-controller gains may be given as time-patterns to optimize the system response as necded.

The current transmitted to the controllers with a $1 \mathrm{~ms}$ time resolution and a 5 A current resolution.

Any pulse pattem can be programmed as long as the design and operation limits of the magnet, the converters and the current controllers are not exceeded.

\section{F. Protection}

If the current of a coil group deviates by a certain amount from the current pattern, the pulse will be aborted by switching the power supplies into the inverter mokle. In case of any relevant alarm, related to a minor problem in any of the systems involved, the pulse will also be aborted. In case of an alarm due to a serious problem in any system, the crowbars will be activated and the generator will be tripfed. 'The crowbar trigger system will be a dual channel system, designed as an extension of the existing dual channel protection system of

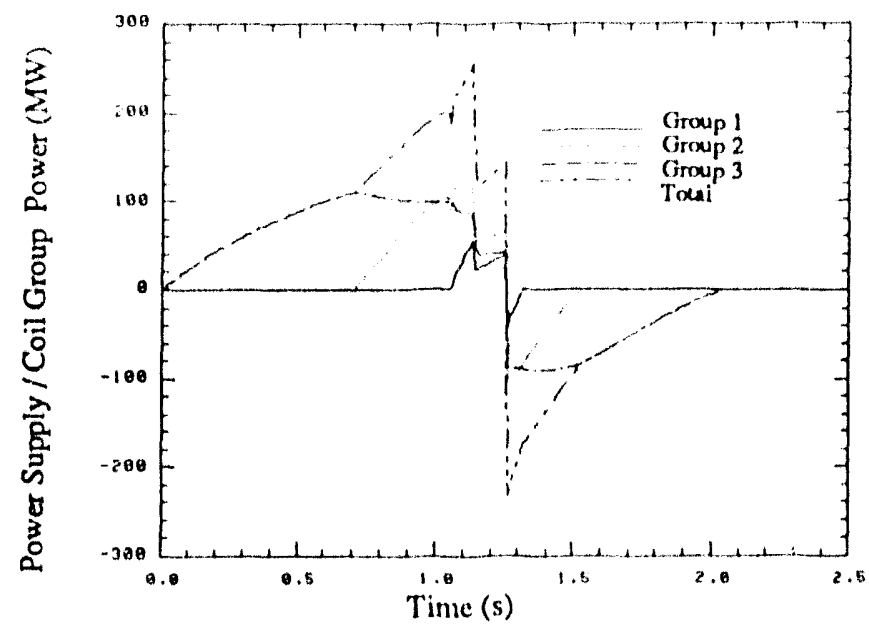

Fig.6. Coil group/power supply power as a function of time

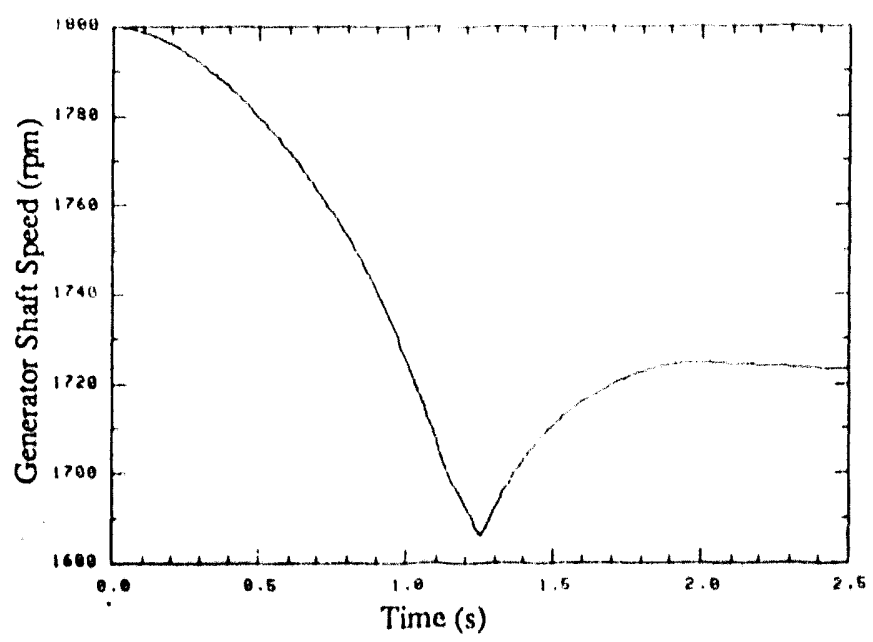

Fig.7. Generator shaft speed as a function of time

the generator system. The magnet protection system will interface with the power supply system and the generator protection system through an inverter-mode command and two independent crowbar-on commands.

\section{ACKNOWLEDGMENT}

The authors would like to thank R. Gribble for his support in modeling of the overall magnet system and patience in resolving the many SCAT- user related "mysteries."

\section{REFERENCES}

(1) H. J. Boenig, J. B. Schillig, H, E. Konkel, P. L. Klingner, T. L. Petersen, J. D. Rogers, "Lesign, Lnstallation and Commissioning of the Los Alamos National Laboratory Pulsed Power Generator," IEEEE Transactions on Energy Conversion, vol. 7. pl. 260.266 , June 1992.

(2) L. J. Campbell, H. J. Bocnig, J. B. Schillig, J. R. Sims et al., "Design and Analysis of High-Ficld Quasi Continuous Magnets," presented at the I3th Magent Technology Con. ference, Victoria, BC, Canada, September 20)-24, 1993. 

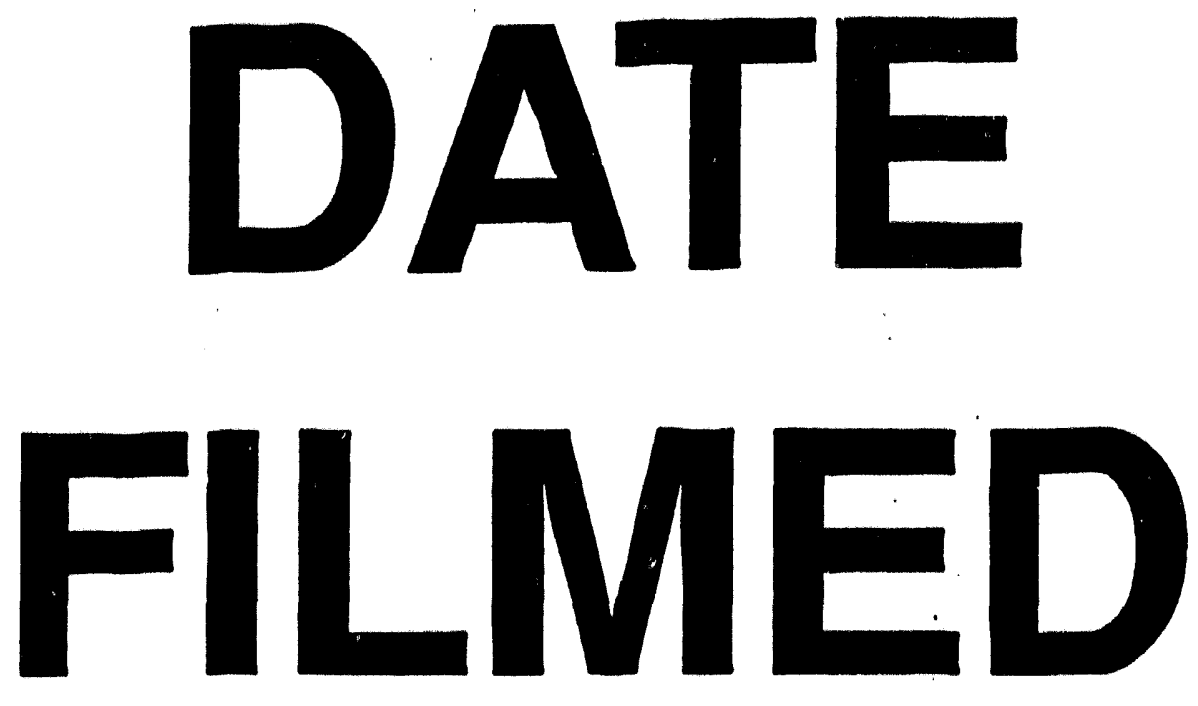

$11 / 17 / 93$
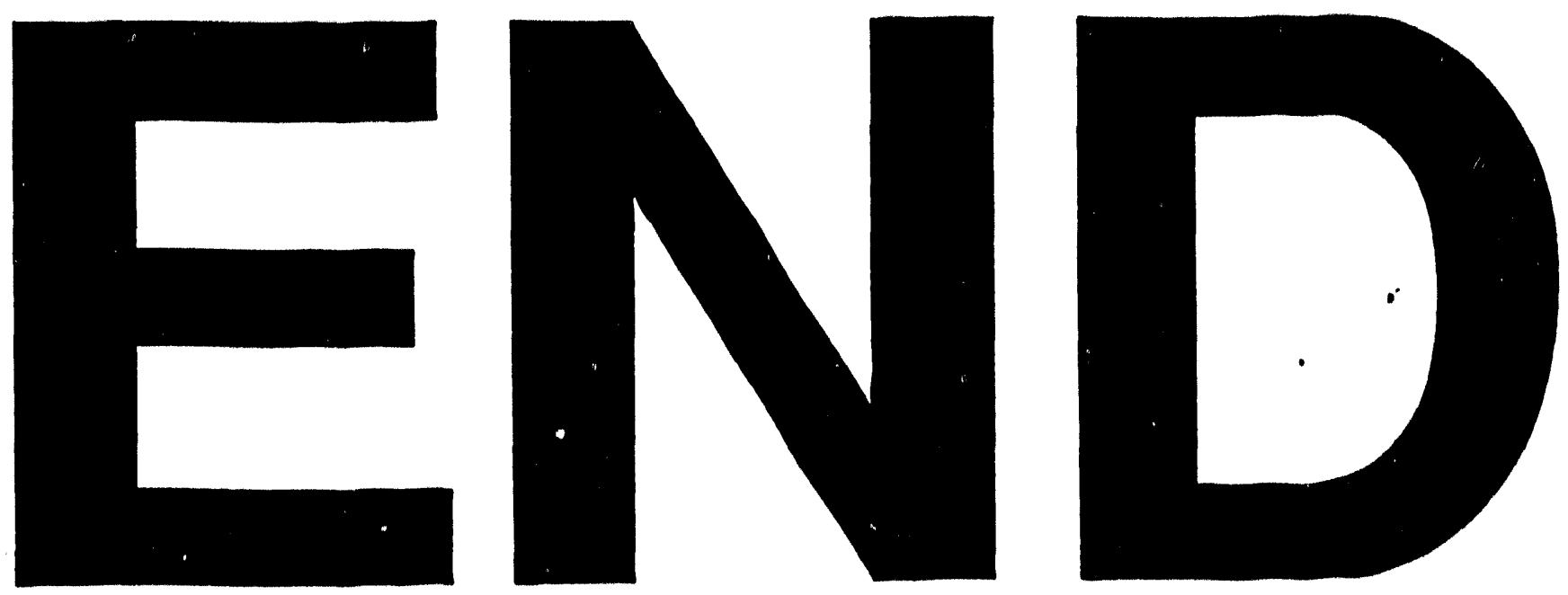
